\title{
Desempenho de bovinos simulado pelo modelo Pampa Corte e obtido por experimentação
}

\author{
Animal performance simulated by Pampa Corte model with experimental records \\ Naíme de Barcellos Trevisan ${ }^{{ }^{*}}$ Vicente Celestino Pires Silveira ${ }^{\text {II }}$ \\ Fernando Luiz Ferreira de Quadros ${ }^{\mathrm{III}}$ Alexandre Coradini Fontoura da Silva ${ }^{\mathrm{I}}$
}

RESUMO

Este trabalho tem como objetivo verificar a confiabilidade do Modelo Pampa Corte na predição de desempenho de bovinos de corte, em sistemas de pastejo. Para tanto, foram confrontados os valores preditos pelo modelo com dados disponíveis na literatura. Foram verificados coeficientes de correlação acima de $90 \%$ entre os dados reais $e$ os simulados em todas as alternativas testadas. $O$ banco de dados do Modelo precisa ser ampliado em termos de alternativas de produtividade das forrageiras, em diferentes condições climáticas. Os parâmetros qualitativos degradabilidade da proteína bruta e fibra em detergente neutro da consorciação aveia preta e azevém necessitam ainda ser pesquisados, assim como o desempenho de animais em pastagens singulares de aveia ou azevém.

Palavras-chave: bovinos de corte, modelos de simulação, bancos de dados de pesquisa.

\section{ABSTRACT}

This study had the objective to evaluate Pampa Corte Model's reliability in predicting beef cattle performance in grazing systems. For this purpose, model's predicted values were compared to available data base of published papers. Correlation coefficients above $90 \%$ were obtained between simulated and real data in all tested alternatives. Model's data base should be enlarged by forage productivity data in different climatic conditions. Mixtures of Italian ryegrass and oat need more studies to obtain qualitative parameters (crude protein degradability and neutral detergent fiber), as well, animal performance in the single pastures of oat or Italian ryegrass.

Key words: Beef cattle, simulation models, research data base.

\section{INTRODUÇÃO}

A análise da produção de alimentos sob o prisma da teoria de sistemas tem aumentado, especialmente com a introdução do conceito das cadeias produtivas no Brasil. Essa teoria apresenta um conjunto de unidades relacionadas, formando um todo ou propiciando a consecução de algum fim lógico a partir de interações conjuntas (BERTALANFFY, 1975). Como cada componente se relaciona com outros, as decisões tomadas em qualquer ponto do sistema possuem impactos diretos e indiretos. Os impactos diretos são facilmente mensuráveis, enquanto que os indiretos, por suas repercussões não serem imediatas, ainda passam despercebidos em muitos casos, mas já são contabilizados em sistemas que priorizam o desenvolvimento sustentável. O auxílio de modelos matemáticos nesses casos é fundamental. Eles são uma forma rápida, de fácil execução e ao mesmo tempo confiável de visualizar diferentes alternativas a serem seguidas pelos produtores e seus respectivos custos. No caso específico da pecuária de corte, modelar cenários significa considerar os pesos das tomadas de decisão dos produtores rurais nos rumos da atividade dentro das propriedades, porém, considerando os fatores externos a estas. Assim, os modelos permitem que sejam adicionados às simulações eventos de natureza independente do produtor, os quais podem

\footnotetext{
'Programa de Pós-graduação em Zootecnia, Universidade Federal de Santa Maria (UFSM). Av. Roraima, 1000, 97105-900, Santa Maria, RS, Brasil. E-mail: naimetrevisan@yahoo.com.br. *Autor para correspondência.

IIDepartamento de Extensão Rural, UFSM, Santa Maria, RS, Brasil.

IIIDepartamento de Zootecnia, UFSM, Santa Maria, RS, Brasil.
} 
modificar os preços de seus produtos (TREVISAN et al., 2006; BARIONI et al., 2003).

Dentre as vantagens que as simulações possuem com relação às formas tradicionais de pesquisa, destaca-se que é menos oneroso, em termos de recursos e tempo, realizar erros em modelos do que nos sistemas reais (FERREIRA et al. , 2002; SILVEIRA, 2002). Considerando os conceitos da teoria de sistemas, SILVEIRA(2002) desenvolveu o modelo Pampa Corte. A ferramenta tem como propósito simular o desempenho de bovinos de corte em sistemas de pastejo. Ela representa um primeiro passo para planejamentos estratégicos em sistemas produtivos. De posse dos dados referentes ao ganho de peso potencial, podem ser simulados diferentes cenários, considerando os custos e o provável retorno de cada alternativa forrageira.

O modelo Pampa Corte faz parte de um sistema integrado de decisões desenvolvido com a finalidade de simular o desenvolvimento corporal de bovinos de corte, de maneira mecanicistica e dinâmica, por meio de equações diferenciais integrais. Para simular o desempenho animal individual, são considerados dois submodelos. O primeiro simula a ingestão e a digestão do alimento e prediz as quantidades diárias de energia e proteína metabólica disponíveis para a produção. O segundo considera essas disponibilidades e prediz as mudanças de peso vivo dos animais (SILVEIRA, 2002). Assim, informações de interesse de produtores rurais são prontamente geradas pelo modelo.

Este trabalho teve como objetivo explorar os resultados de experimentos disponíveis na literatura visando verificar a confiabilidade do Modelo Pampa Corte. Os dados das pastagens cultivadas de aveia preta, azevém e milheto com e sem suplementação e de pastagem natural sem utilização de suplemento foram utilizadas, visto que essas dietas são freqüentemente usadas em sistemas de terminação de bovinos de corte no Rio Grande do Sul (RS).

\section{MATERIAL E MÉTODOS}

O banco de dados reais utilizado teve como base resultados experimentais disponíveis e adequados aos objetivos do trabalho. A escolha destes teve dois critérios: a disponibilidade das informações que o modelo demanda como entrada e os resultados de desempenho animal a serem comparados com as respostas do modelo.

São necessárias as seguintes informações dos animais: grupo genético, idade e peso inicial como dados de entrada, bem como ganho médio diário e peso final para verificação dos dados reais com os simulados. Em relação à pastagem são necessárias informações da qualidade e quantidade da dieta, as quais consistem em: espécie, manejo dos animais (entrada e período de utilização), fibra em detergente neutro (FDN), proteína bruta (PB), degradabilidade da PB e FDN, considerando a taxa de passagem de $5 \%$ por hora $\left(5 \% \mathrm{~h}^{-1}\right)$. Também são requeridas pelo modelo informações diárias do clima do local em que o experimento foi desenvolvido, tais como: temperaturas máxima, mínima e média, umidade relativa do ar, velocidade do vento e precipitação total. Quando essas não estavam disponíveis na publicação, foram tomados os dados meteorológicos das estações mais próximas do sítio experimental.

Outro critério para a escolha dos trabalhos foi sua semelhança com a realidade dos sistemas de produção de animais no Rio Grande do Sul: pastagem cultivada de aveia preta (Avena strigosa Schreb.) e/ou azevém anual (Lolium multiflorum Lam.) com ou sem suplementação e pastagem cultivada de milheto (Pennisetum americanum) com e sem suplementação. Estes sistemas representam a realidade de produtores da região do Planalto do Rio Grande do Sul, onde essas espécies são cultivadas num sistema de integração lavoura-pecuária. Além destas, foram utilizadas informações sobre o desempenho de animais em pastagens naturais pela abrangência deste recurso forrageiro nas regiões Sul e Sudoeste, bem como pela disponibilidade de informações mais completas para formar o banco de dados de entrada do modelo.

As informações disponíveis nos trabalhos estão detalhadas na tabela 1. Do trabalho de PRADO et al. (2003), foram retiradas informações sobre qualidade da aveia preta e milheto, bem como desempenho dos animais mantidos nestas pastagens. As informações publicadas por SANTOS et al. (2004) foram importantes para verificar a confiabilidade do Pampa Corte quanto ao desempenho de novilhas em pastagem de milheto suplementadas com polpa cítrica. LUPATINI (1996) forneceu informações de produção animal em pastagem exclusiva de milheto. Da mesma forma foram utilizados os dados de SOUZA et al. (1992) sobre novilhos das raças Hereford e Angus em aveia preta; SORGATTO (2000) e ARALDI (2003), que trabalharam com novilhos Braford em pastagem natural, e ILHA et al. (2006), que trabalharam com bovinos de corte em pastagem exclusiva de azevém.

O banco de dados do modelo Pampa Corte inclui três situações climáticas pré-estabelecidas à disposição para serem acrescentadas às simulações. Por clima bom entendem-se aqueles conjuntos de anos em que o total de precipitações anuais está bem distribuído durante os meses. O clima regular corresponde a déficits hídricos durante os meses mais 
Tabela 1 - Dados pesquisados na literatura referentes a desempenho animal em pastagens e à qualidade das forrageiras.

\begin{tabular}{|c|c|c|c|c|c|c|c|c|c|}
\hline \multicolumn{10}{|c|}{ Dados referentes à pastagem para entrada no Pampa Corte } \\
\hline \multirow[b]{2}{*}{ Referência } & \multirow[b]{2}{*}{ Espécie } & \multicolumn{4}{|c|}{--------------Dados Quantitativos-------------- } & \multicolumn{4}{|c|}{-----------------Dados Qualitativos---------------- } \\
\hline & & $\begin{array}{c}\text { Data de entrada } \\
\text { animais }\end{array}$ & $\begin{array}{l}\text { Período } \\
\text { utilização } \\
\text { (dias) }\end{array}$ & $\begin{array}{r}\text { Disponib } \\
\text { forrageir } \\
\text { ha }^{-1} \mathrm{I}\end{array}$ & $\begin{array}{l}\text { lidade } \\
\text { IS) }\end{array}$ & $\mathrm{FDN}^{*}(\%)$ & $\mathrm{PB}^{*}(\%)$ & $\begin{array}{l}\mathrm{DFDN}^{*} \\
\left(5 \% \mathrm{~h}^{-1}\right)\end{array}$ & $\begin{array}{c}\text { DPB* } \\
\left(5 \% h^{-1}\right)\end{array}$ \\
\hline $\begin{array}{l}\text { PRADO et al. } \\
\text { (2003) }\end{array}$ & Aveia preta & 07 jul 2000 & 73 & 2000 & & 62,53 & 12,51 & 39,7 & 70,7 \\
\hline $\begin{array}{l}\text { PRADO et al. } \\
(2003)\end{array}$ & Milheto & 30 nov 2000 & 56 & 2000 & & 61,38 & 11,26 & 34,8 & 64 \\
\hline $\begin{array}{l}\text { SANTOS et al. } \\
(2004)\end{array}$ & $\begin{array}{l}\text { Milheto + } \\
\text { Grão de } \\
\text { milho moído }\end{array}$ & 16 fev 2001 & 64 & $1800 \mathrm{a}$ & 2000 & - & - & - & - \\
\hline $\begin{array}{l}\text { LUPATINI } \\
(1996)\end{array}$ & Milheto & 31 dez 1993 & 106 & 1638 & & - & - & - & - \\
\hline $\begin{array}{l}\text { SOUZA et al. } \\
(1992)\end{array}$ & Aveia preta & 14 jun 1988 & 98 & 1200 & & - & - & - & - \\
\hline $\begin{array}{l}\text { ARALDI } \\
(2003)\end{array}$ & $\begin{array}{l}\text { P. Natural } \\
\text { (Bagé, RS) }\end{array}$ & 17 maio 1999 & 322 & $1800 \mathrm{a}$ & 2000 & - & - & - & - \\
\hline $\begin{array}{l}\text { ILHA et al. } \\
(2006)\end{array}$ & Azevém & 05 ago 2003 & 71 & 1300 & & - & - & - & - \\
\hline \multirow[b]{2}{*}{ Referência } & ------------ & ---------Dados de entrá & da no Pamp & Corte------ & --------. & \multicolumn{4}{|c|}{ Dados p/ comparação com simulações } \\
\hline & Sexo & Grupo genético & \multicolumn{2}{|c|}{ Peso inicial (kg) } & Idade ( & meses) Gal & $\begin{array}{l}\text { ho diário (kg } \\
\mathrm{an}^{-1} \mathrm{dia}^{-1} \text { ) }\end{array}$ & \multicolumn{2}{|c|}{ Peso final (kg) } \\
\hline $\begin{array}{l}\text { PRADO et al. } \\
\text { (2003) }\end{array}$ & machos & Nelore & \multicolumn{2}{|c|}{380} & - & & 0,580 & \multicolumn{2}{|c|}{438} \\
\hline $\begin{array}{l}\text { PRADO et al. } \\
(2003)\end{array}$ & machos & Nelore & \multicolumn{2}{|c|}{397} & - & & 0,880 & \multicolumn{2}{|c|}{447} \\
\hline $\begin{array}{l}\text { SANTOS et al. } \\
(2004)\end{array}$ & fêmeas & $\begin{array}{l}\text { Cruzamento Charo } \\
\text { Nelore, Hereford } \\
\text { Angus }\end{array}$ & \multicolumn{2}{|c|}{95,5} & 3 & & 0,611 & \multicolumn{2}{|c|}{134,60} \\
\hline $\begin{array}{l}\text { LUPATINI } \\
(1996)\end{array}$ & fêmeas & Charolês X Nelore & \multicolumn{2}{|c|}{184} & 1 & & 1,082 & \multicolumn{2}{|c|}{298,69} \\
\hline $\begin{array}{l}\text { SOUZA et al. } \\
(1992)\end{array}$ & machos & Aberdeen Angus & \multicolumn{2}{|c|}{288} & 1 & & 0,905 & \multicolumn{2}{|c|}{376,69} \\
\hline $\begin{array}{l}\text { SOUZA et al. } \\
(1992)\end{array}$ & machos & Hereford & \multicolumn{2}{|c|}{310} & 4 & & 1,370 & \multicolumn{2}{|c|}{444,26} \\
\hline $\begin{array}{l}\text { ARALDI } \\
(2003)\end{array}$ & machos & Braford & \multicolumn{2}{|c|}{170} & 1 & & 0,480 & \multicolumn{2}{|c|}{324,46} \\
\hline $\begin{array}{l}\text { ILHA et al. } \\
(2006)\end{array}$ & fFêmeas & Charolês X Nelore & \multicolumn{2}{|c|}{160,8} & 9 & & 0,857 & \multicolumn{2}{|c|}{223,2} \\
\hline
\end{tabular}

*Legenda:FDN- Fibra em Detergente Neutro; PB- Proteína Bruta; DFDN- Degradabilidade da Fibra em Detergente Neutro considerando taxa de passagem de 5\% por hora; DPB- Degradabilidade da Proteína Bruta considerando taxa de passagem de 5\% por hora.

quentes do ano, porém, por períodos que não chegam a caracterizar estiagem. Quando o volume de chuvas anuais está bastante concentrado nas estações frias e no verão e o acúmulo de água no solo e nos mananciais é restrito por mais de 15 dias, o clima é classificado como ruim.

Variações climáticas são especialmente importantes para determinar o crescimento em potencial das pastagens. Assim, a comparação do desempenho real de animais em sistemas de pastejo foi feita com três prováveis resultados simulados de acordo com as alternativas climáticas descritas.
Depois de realizadas as simulações, foram calculados os coeficientes de correlação e determinação entre dados reais e aqueles gerados pelo Modelo utilizando o programa XL STAT (2007).

Com os trabalhos que continham várias datas de avaliação, foi realizada análise de regressão, assim, foi feita a comparação entre as equações dos resultados reais e as dos valores simulados, assumindo a probabilidade de $95 \%$ para o intervalo de confiança. Quando os trabalhos dispunham apenas dos pesos inicial e final dos animais, os resultados foram comparados apenas pelo coeficiente de correlação. 


\section{RESULTADOS E DISCUSSÃO}

Um dos fundamentos do estudo de sistemas por meio da modelagem é apontar as carências de dados das pesquisas existentes até o momento. A definição dos objetivos das pesquisas para elucidar esses pontos carentes permitiria um maior avanço científico. Neste trabalho, alguns desses gargalos são apresentados. A consorciação das espécies aveia preta e azevém, embora bastante difundida nos sistemas de produção pecuários gaúchos, ainda não foi suficientemente avaliada quanto à degradabilidade da proteína bruta como parâmetro qualitativo. Da mesma forma, não foram encontrados dados correspondentes ao desempenho de animais suplementados nas pastagens singulares de azevém ou aveia preta. Isso limitou o leque de comparações entre os sistemas reais e simulados pelo Pampa Corte.

O modelo Pampa Corte foi eficiente em simular respostas de desempenho das categorias de novilhas cruzas Charolês e Nelore em recria sobre pastagem de milheto e novilhos das raças Angus e Hereford em terminação sobre aveia preta, conforme descrito na figura 1 . O coeficiente de determinação entre esses dados e suas simulações foi de 0,99.

A simulação do processo digestivo e da utilização dos nutrientes para permitir incremento de tecido corporal permitiu ao modelo prever o desempenho animal com grande precisão, apresentando valores próximos aos reais. Os valores estimados variaram cerca de $6 \%$ para mais ou menos dos pesos reais, havendo pequena superestimação $(1,5 \%)$ no caso dos novilhos Angus.

O planejamento de estratégias produtivas por períodos anuais ou maiores adquire confiabilidade no momento em que as projeções sobre desempenho animal possuem elevado grau de acurácia. O fator clima, incontrolável pelo homem e determinante da produtividade potencial das forrageiras nativas e cultivadas e, em conseqüência, do desempenho de animais em pastejo, é incorporado nas simulações. Isso permite tornar previsíveis extremos máximos e mínimos de produção de peso vivo resultantes dos sistemas projetados.

Os desempenhos animais em pastagem natural simulados pelo Pampa Corte foram correlacionados positivamente com $\mathrm{R}=0,97$ aos dados publicados por SORGATTO (2000). Conforme apresentado na figura 2, o modelo prediz respostas diferentes de produção de novilhos Braford de acordo com distintas situações climáticas, sendo o pior coeficiente de determinação $\left(\mathrm{R}^{2}\right)$ obtido de 0 , 82. Este e os demais valores de $\mathrm{R}^{2}$, aliados ao fato de os pontos que geraram a regressão estarem dentro do intervalo de confiança de $95 \%$, demonstram a confiabilidade das predições do modelo.

Os resultados do modelo apresentaram correlação positiva $(\mathrm{R}=0,96)$ com os dados de desempenho de novilhos Braford em pastagem natural registrados por ARALDI (2003). O trabalho da autora corresponde a uma seqüência das pesquisas de SORGATTO (2000). As curvas de regressão dos dados podem ser visualizadas na figura 3 , que apresentam uma disposição dos pontos semelhantes à figura 2, dentro do mesmo intervalo de confiança, sendo nesse caso o pior valor de $\mathrm{R}^{2}=0,90$.

Pelas equações de regressão, se o clima anual for ruim, seriam necessários 5,81 dias para que novilhos Braford ganhassem um quilo de peso vivo em pastagem natural da região de Bagé. Esse período de tempo seria reduzido para 4,18 dias se a situação climática do ano fosse regular, bem como 3,22 dias em clima favorável. Segundo MOOJEN \& MARASCHIN (2002), o desempenho com oferta baixa (4kg de MS $100 \mathrm{~kg}$ de $\mathrm{PV}^{-1}$ ) seria de $0,15 \mathrm{~kg}$ animal ${ }^{-1} \mathrm{dia}^{-1}$, muito próximo do valor previsto para clima ruim, ou seja, com restrições ao consumo dos animais. O valor mais elevado, com clima favorável, equivale aos $0,31 \mathrm{~kg}$ $\mathrm{dia}^{-1}$ registrados por SOARES et al. (2005).

A interpretação das simulações e dos resultados registrados por SORGATTO (2000) e ARALDI (2003) indica que as condições climáticas e a oferta de forragem não limitaram a produção da pastagem natural e, conseqüentemente, o desempenho animal durante a condução dos experimentos. No entanto, o modelo apresentou maior precisão quando confrontado com os pesos dos animais de maio até outubro. Isso pode estar associado ao banco de dados utilizado para as simulações, que corresponde à pastagem natural do CPPSul/EMBRAPA, no município de Bagé, RS. Esses dados foram coletados em anos de precipitações mal distribuídas, durante o período primavera-verão. Além disso, a qualidade do solo é inferior à qualidade dos solos onde foram realizados os experimentos, o que pode ter prejudicado os parâmetros qualitativos utilizados pelo modelo. Conseqüentemente, as saídas do modelo demonstraram produção animal inferior às observadas por SORGATTO (2000) e ARALDI (2003).

Quando apenas uma espécie forrageira é considerada num período avaliado menor que um ano, o Pampa Corte apresenta maior confiabilidade. Isso pode ser visualizado na figura 4 , na qual os coeficientes 


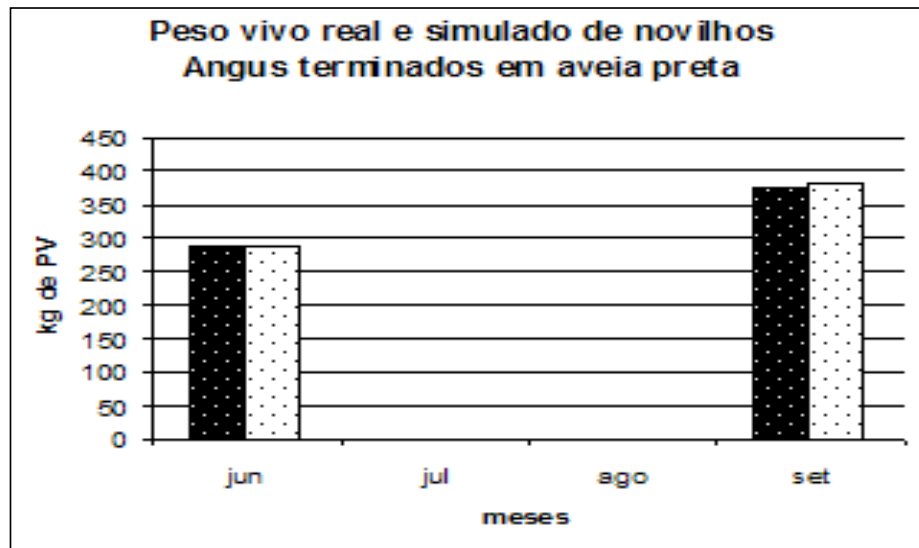

Pesos vivos reais e simulados de novilhos Hereford em aveia preta

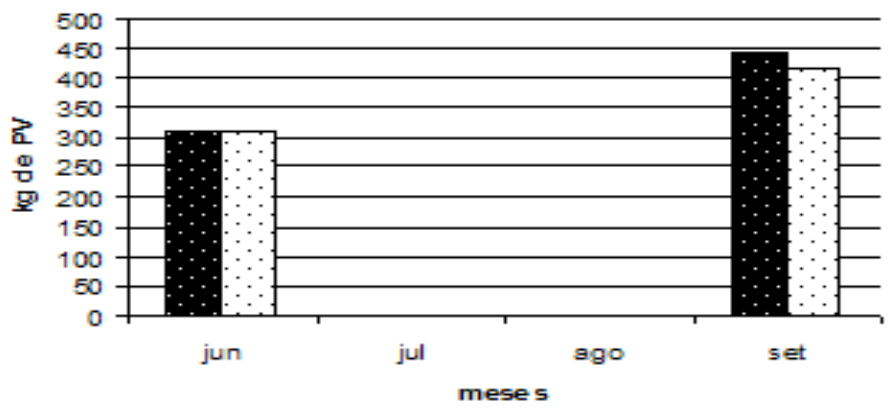

Pesos viv os reais e simulados de novilhas Cha rolêsx Nelore em milheto suplementa das com polpa cítrica

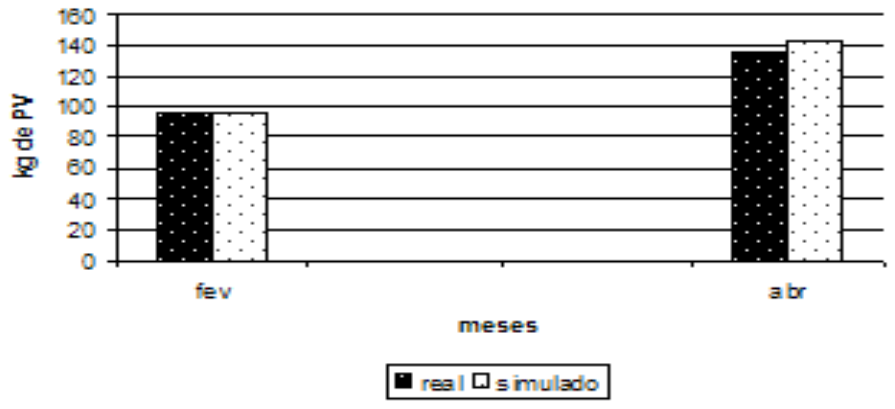

Figura 1 - Comparação do desempenho real e do simulado pelo Pampa Corte de novilhos Angus e Hereford em pastagem de aveia preta (SOUZA et al., 1992) e novilhas cruza Charolês e Nelore em pastagem de milheto suplementadas com polpa cítrica (SANTOS et al., 2002)

de determinação dos resultados simulados resultaram em 0,99 e 0,90, em sistemas de pastejo em azevém e milheto, respectivamente. A produção animal simulada em azevém e milheto apresentou correlação positiva de 0,99 em relação aos dados reais. Ao comparar os valores obtidos em pastagens monoespecíficas com os resultados indicados na figura 1 , observamos uma grande similaridade entre os coeficientes de correlação, o que reforça a hipótese da maior sensibilidade do modelo para essas situações.

A maior sensibilidade está associada à menor variabilidade dos parâmetros qualitativos em pastagens anuais e ao fato destas serem manejadas em condições não-limitantes de oferta de forragem nos 


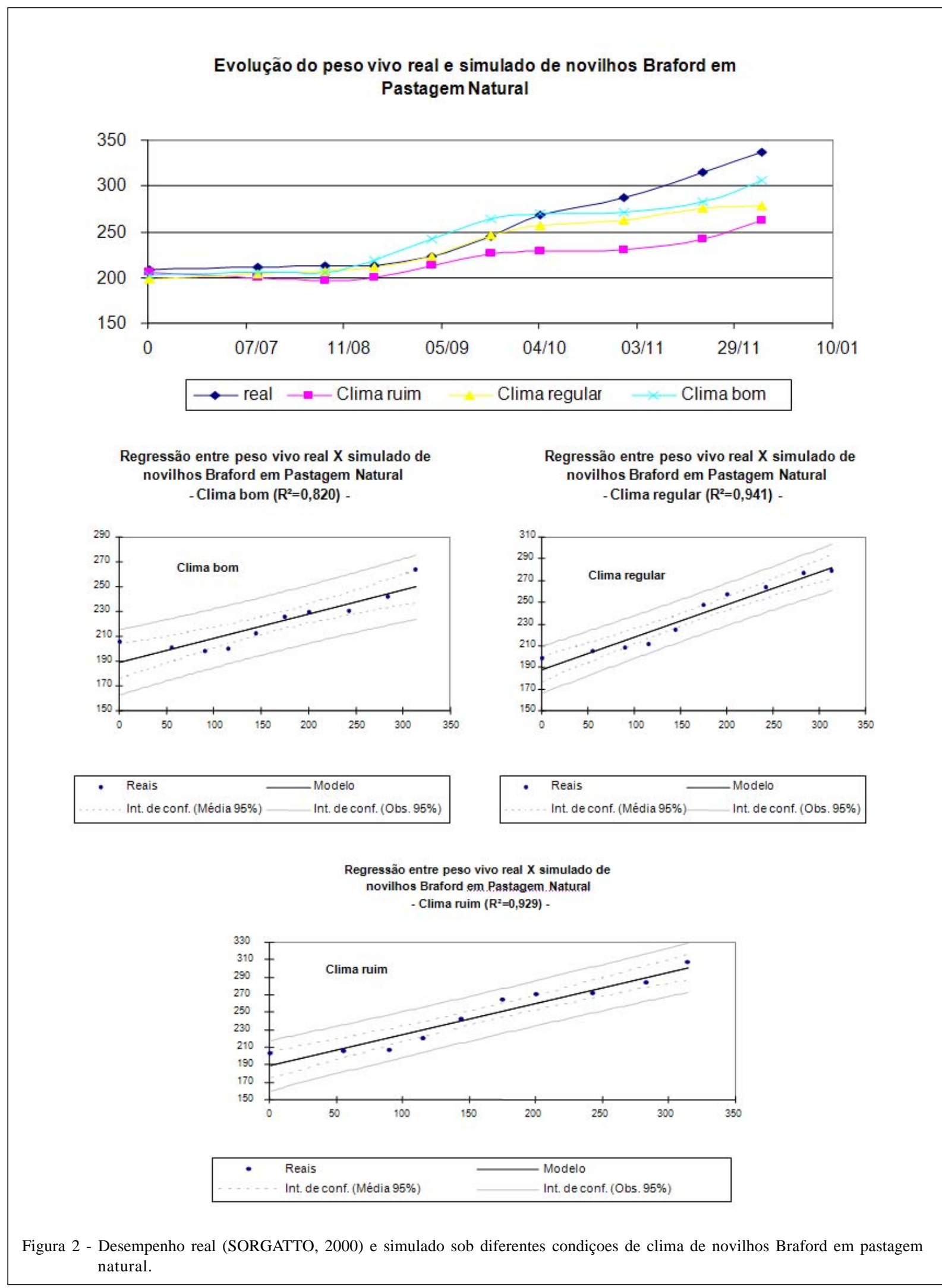

Ciência Rural, v.39, n.1, jan-fev, 2009. 


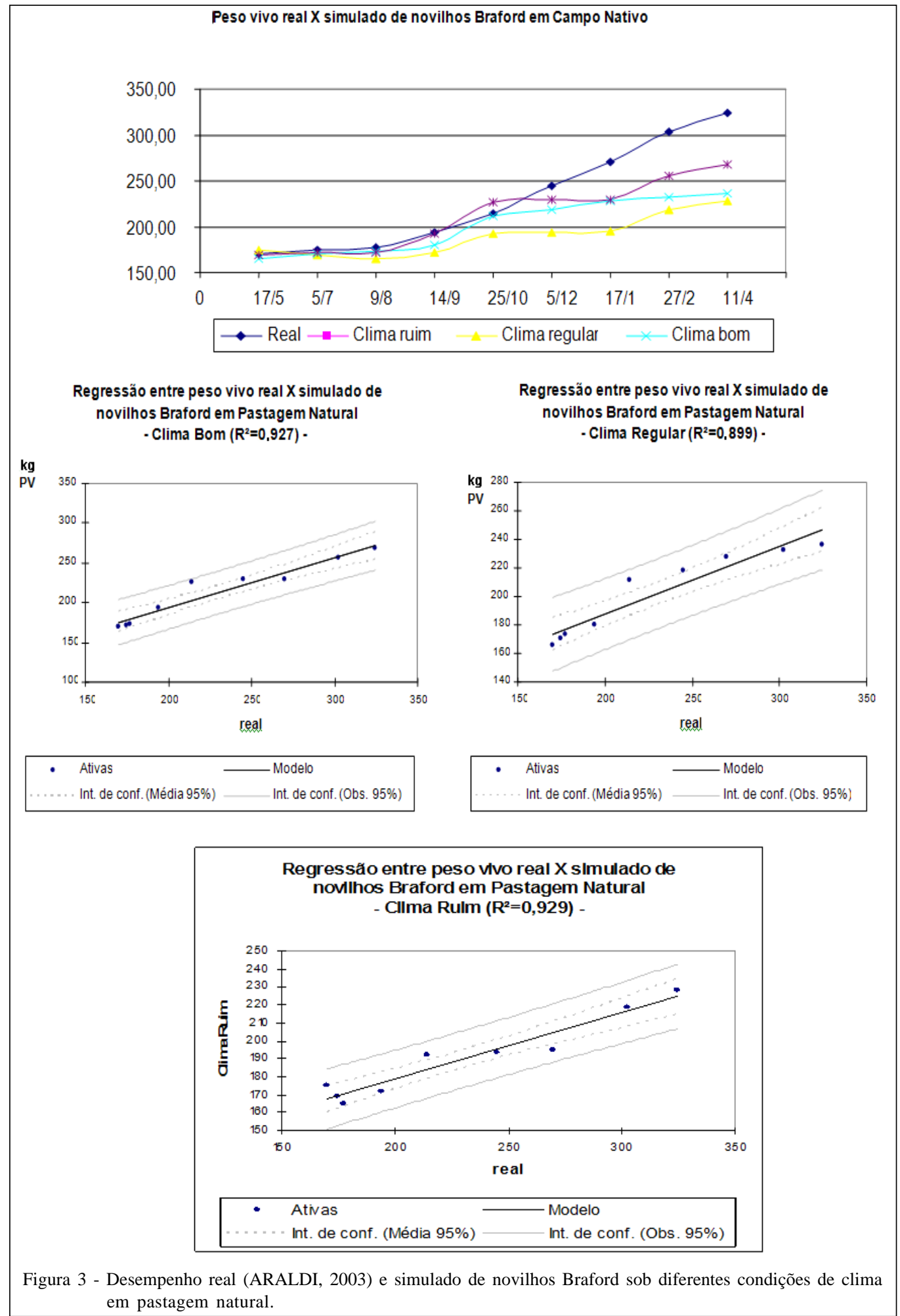

experimentos citados na figura 4. As análises de regressão demonstram que, durante um período médio de 90 dias de utilização das pastagens cultivadas, novilhas cruza Charolês-Nelore seriam capazes de ganhar 79,2kg PV em azevém e 95,4kg PV em milheto. Isso significa que seriam necessários 1,16 dias para cada quilo ganho na opção de estação fria e 0,94 dia na alternativa de pastagem de estação quente.

Ciência Rural, v.39, n.1, jan-fev, 2009. 


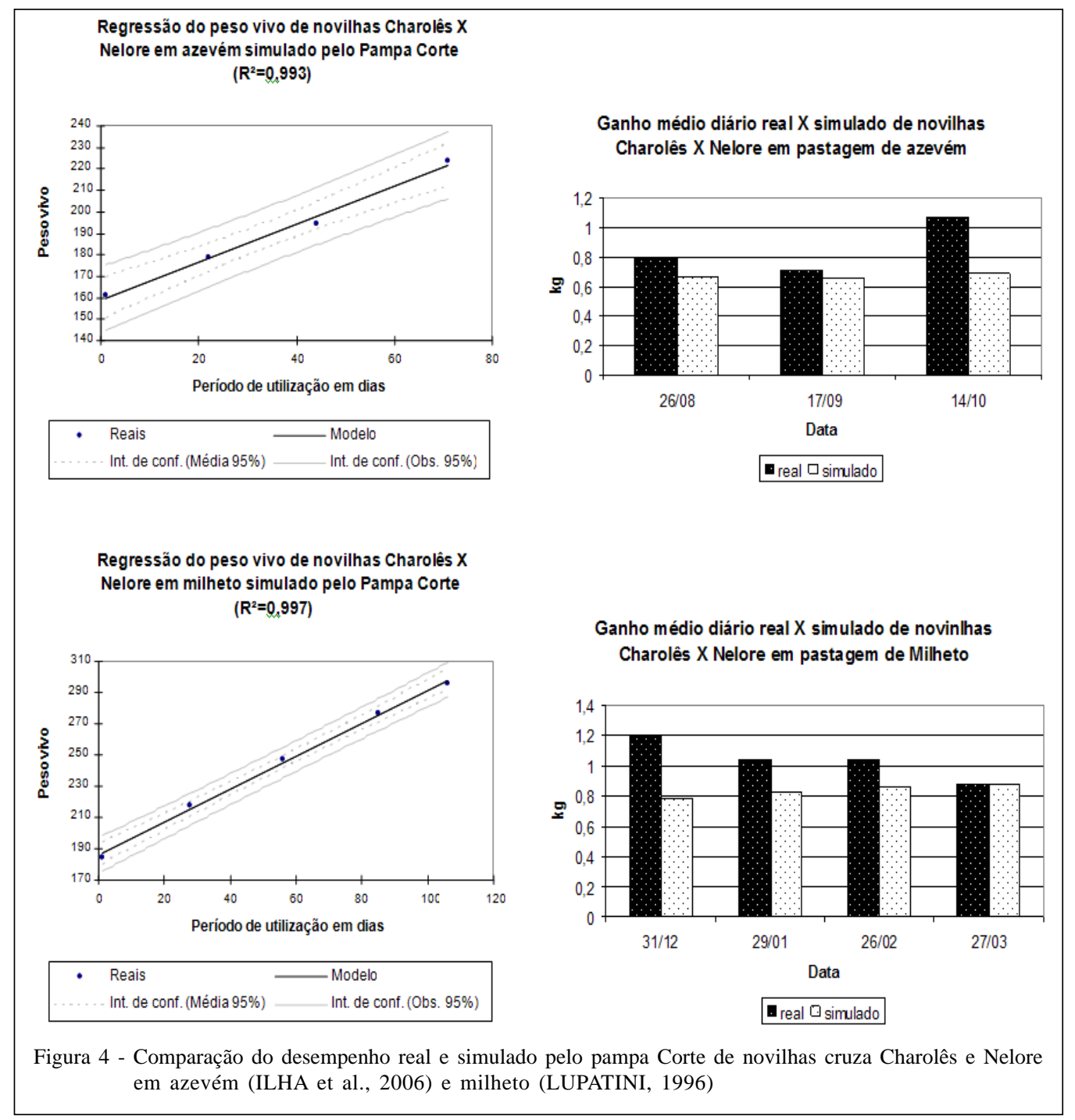

\section{CONCLUSÕES}

O modelo Pampa Corte é eficiente em produzir respostas de desempenho animal em sistemas de pastejo. Porém, o banco de dados do Modelo precisa ser ampliado quanto à produtividade das forrageiras em diferentes condições climáticas.

Existe carência de pesquisas sobre qualidade da consorciação de aveia preta e azevém quanto ao parâmetro degradabilidade da proteína bruta. Também se faz necessária a promoção de pesquisas sobre desempenho de bovinos de corte suplementados nas pastagens singulares de aveia ou azevém.

\section{REFERÊNCIAS}

ARALDI, D.F. Avaliação de pastagem natural e pastagem sobre-semeada com espécies invernais com e sem uso de glifosato. 2003. 111f. Dissertação (Mestrado em Zootecnia) - UFSM, Santa Maria, RS.

BARIONI, L. G. et al. Planejamento e gestão do uso de recursos forrageiros na produção de bovinos em pastejo. In: PEIXOTO, A.M. et al. (Org.). Pastagens. Piracicaba: FEALQ, 2003. p.105154.

BERTALANFFY, V. Teoria geral dos sistemas. 2.ed. Petrópolis: Vozes, 1975. 351p.

FERREIRA, G. et al. Modelo bio-economico para a toma de decisiones em engorde de novillos a pastoreo. In: In: EVERLING, D.M. et al. Modelos para a tomada de decisões na produção de bovinos e ovinos. Santa Maria, Pallotti, 2002. p.121. 231p. 
ILHA, G.F. et al. Desempenho de bezerras em diferentes alternativas de utilização da pastagem de azevém “Lolim multiflorum Lam.”. In: REUNIÃO ANUAL DA SOCIEDADE BRASILEIRA DE ZOOTECNIA, 43., 2006, João Pessoa, PB. Anais... Joao Pessoa: Sociedade Brasileira de Zootecnia, 2006. CD ROM.

LUPATINI, Produção animal em milheto submetido a níveis de adubação nitrogenada. 1996. 202f. Dissertação (Mestrado em Zootecnia) - UFSM, Santa Maria, RS.

MOOJEN, E.L.; MARASCHIN, G.E. Potencial produtivo de uma pastagem nativa do Rio Grande do Sul submetida a níveis de oferta de forragem. Ciência Rural, v.32, n.1, p.127-132, 2002.

PRADO, I.N. et al. Sistemas para crescimento e terminação de bovinos de corte a pasto: avaliação do desempenho animal e características da forragem. Revista Brasileira de Zootecnia, v.32, n.4, p.995-965, 2003.

SANTOS, D.T. et al. Suplementos energéticos para a recria de bovinos de corte em pastagens anuais. Revista Brasileira de Zootecnia, v.33, n.6, p.2359-2368, 2004.
SILVEIRA, V.C.P. Pampa corte - um modelo de simulação para o crescimento e engorda de gado de corte. Ciência Rural, v.32, n.3, p.543-552, 2002

SOARES, A.B. et al. Produção animal e de forragem em pastagem nativa submetida a distintas ofertas de forragem. Ciência Rural, Santa Maria, v.35, n.5, p.1148-1154, 2005.

SORGATTO, D. Avaliação de pastagem natural e pastagem sobre-semeada com espécies invernais com e sem uso de glifosato. 2000. 114f. Dissertação (Mestrado em Zootecnia) - UFSM, Santa Maria, RS.

SOUZA, J.M. et al. Terminação de bovinos em pastagem de aveia preta. In: Pesquisa no centro de treinamento da Cotrijuí. Ijuí: Cotrijuí, 1992. 278p.

TREVISAN, N.B. et al. Simulações econômicas de cenários tecnológicos para a produção de bovinos destinados à Aliança Mercadológica no Rio Grande do Sul. In: ENCONTRO DE ECONOMIA GAÚCHA, 3., 2006 PUC-RS. Acesso em 17 jan. 2007. On line. Disponível em < http:// www.fee.tche.br/3eeg/Artigos/m13t01.pdf>.

XL STAT - Statistical software for MS Excel. Acesso em 17 jan. 2007. On line. Disponível em <http://www.xlstat.com>. 